\title{
Does flood risk information held within at risk population always have a positive impact? An evaluation of the effects of French regulatory tools in Orleans
}

\author{
Julien Jadot ${ }^{1, a}$, Cathy Gemon ${ }^{1}$, Isabelle Richard ${ }^{2}$, and Nicolas Bauduceau ${ }^{1}$ \\ ${ }^{1}$ Centre Européen de Prévention du Risque Inondation (CEPRI), Orléans, France \\ ${ }^{2}$ Senior researcher and consultant in environmental psychology, Environnons, Paris, France
}

\begin{abstract}
French law on major risk preventive information for population setup the objective to make the citizen able to act for his own safety and to participate through his behaviour to the civil security. To reach this objective, the policymakers developed 4 regulatory tools that have to be implemented by the local authorities. These 4 tools do not meet the success factors of risk communication measures aiming at inducing behavioural adaptation to face risks. This, added to the fact that people who die in the last floods events in France lost their lives due to either a lack of knowledge of the risk or to a risk taking behaviour, led us to question the impact of the preventive information regulatory tools. For the needs of our study we developed a risk perception and behaviour scale, helping us to classify the people of our sample. Our evaluation in Orléans shows that very few people know the regulatory tools and that their impact is quite low, far from the policymakers' expectations. This highlight the real necessity to innovate in the field of flood risk communication.
\end{abstract}

\section{Introduction: behaviour of French population at risk population facing a flood, is there a problem?}

With 17 million of persons living in the flood prone zones (1/4 of the total population) and $1 / 3$ of the jobs located in the same areas [1], France is highly exposed to flood risk.

French population appears to not feel really concerned by this risk. The national barometer on water resources and wetlands preservation [2] shows that the interviewees place flood management in the last position of the list of the most important stakes regarding water related issues. It is quoted by only $15 \%$ of the interviewees. This study has been held only little time after two catastrophic floods in France which in 2010 killed 67 people (Atlantic coast flooded due to Xynthia and the Var department impacted by a flash flood event). One year later, these 2 important events seem not having any more influence on how the interviewees perceive the stakes of flood risk.

Studies notice that fatalities in case of flood are for an important part due to "risk-taking behaviours or to an underestimation of the danger", in the Var, notably, "this more active vulnerability of the persons suggest a responsibility of the victim and a risk taking" [3]. More recently, in 2014, about 20 persons died in floods, for 5 of them, the death can be considered to be due to an inadequate behaviour.
Besides the death casualties, inadequate behaviours in case of flooding may impair efficiency of the authorities' actions to manage the crisis and increase the negative impacts of floods.

It worth noting that only $15 \%$ of the persons exposed to one or many risks, know about the recommendations of the authorities to protect themselves from the risks they have to face [4].

The low concern of the population regarding the flood risk combined to the too widespread misreading of the risks and inadequate behaviours has substantial impacts on the consequences of the floods events hitting France.

However we notice that in France, since 1987, the citizen has the right to be informed about the major risks he is exposed to. This information is called "preventive information". In this frame, the policymakers progressively institute 4 regulatory tools that have to be implemented. The municipal document for information on major risks (DICRIM - Document d'Information Communal sur les Risques Majeurs), the flood marks, and the public meetings have to be implemented by the mayor. The buyers and tenant information (IAL Information Acquéreur Locataire) has to be implemented by the private sector.

CEPRI and Nîmes University identified success factors of population risk information in order to improve the behaviours in front of flood risk and shown that these

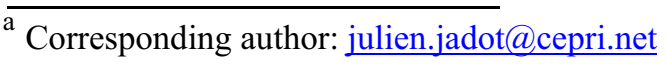


4 tools were taking in consideration only very few of these factors $[5,6]$.

Low knowledge of the population on flood risk and recommendations, inadequate behaviours leading to death, tools not fitting with success factors, all these points question the effectiveness and the impact of the flood risk information on the citizen. To provide a picture of the situation, we led an evaluation of the impact of these 4 tools in the city of Orléans (France). It brings interesting results that this paper will present after the methodology aspects of the study.

\section{A State with ambitious objectives and a questionable set of tools}

\subsection{What are the State objectives regarding risk communication?}

\subsubsection{Interesting and ambitious objectives...}

In 1987, after a succession of many natural or technological catastrophes in the 1st semester of the year, the policymakers decided a new law introducing the right for the citizen to be informed about the risks, natural and technological, he faces in his daily life. Since, different laws modified this first text, they increased the level of expectations in terms of behaviour of populations exposed to major risks. The last law on this topic, the law of modernisation of the civil security of 2004 [7], induce a noticeable change. The responsibility of the citizen shifts from a role restricted to the household domain to a responsibility and active role in the civil security. The law states that: "civil security is everybody's business. Each citizen participates in with his behaviour. » [7]

These objectives are summarised in the DICRIM elaboration guidelines [8]: "Information of the citizen on natural and technological major risks is a right written in the law since 1987 . It should allow anybody to know the hazards he is exposed to, the predictable damages, the preventives measures he can anticipates to reduce his vulnerability, the appropriate behaviours in front of the danger or in case of warning and also the means of protection and rescue implemented by the public authorities. It is an essential condition to be an active participant to the security.

Otherwise, preventive information contributes to build a collective memory, to ensure solidarity, to strengthen the social tie and to maintain the compensation mechanisms."

This list has to be completed with the objective to allay the fears.

\subsection{2. ... Based on a theory of action}

Looking briefly at the theory of action of the preventive information, we noticed that it is based on 2 statements.

The preventive information is not an obligation to inform but a right of the citizen to access to the information, which suggests an active role of the population to get the information on the risk it is exposed to.

With the knowledge acquired on the risk, the predictable damages, the actions of the authorities in prevention and in crisis and the adapted behaviours, the citizen, will allay his fears and empower himself and adapt his behaviour. And by doing so, he will participate actively to the civil security.

\subsection{What are the tools to reach this target?}

To reach these objectives to raise the knowledge of the exposed populations, to bring them to act to anticipate an event and to react appropriately in front of a catastrophe, to be an active component of the civil security, the State elaborated 4 main regulatory tools.

\subsubsection{The public meetings}

They have to be implemented in the cities covered by a Flood Risk Prevention Plan (Plan de Prévention du Risque inondation $-\mathrm{PPRi}^{\mathrm{a}}$ ). The information to provide is: characteristics of the natural risks the commune is exposed, prevention and safeguarding measures, measures of the PPRi, warning system, rescue services organisation, measures the municipality implement to manage the risks and the insurance coverage.

The mayor implements the public meetings in his municipality, with the support of the Prefect and of the local State services.

The scope of the meetings and way the information about the meetings reach the population are not given by the law.

\subsubsection{The DICRIM}

The DICRIM has to be implemented in the cities as mentioned in the Environment law ${ }^{\mathrm{b}}$, notably those concerned by a PPRi. The mayor is in charge of implementing the DICRIM, with the support of the Prefect who provide him with the required information to elaborate the document.

The DICRIM is a booklet or a brochure, mainly in paper, possibly in digital format. The document has to use visual support as maps and has to present popularized information. The document presents the major risks concerning the city and their consequences, the prevention, safeguard and protection measures, a list of the past events, the alert and rescue organisation, the basic reactions recommended and individual instructions. It also includes a list of the flood marks if the city is in flood prone area.

The DICRIM can be read for free at the city hall and, if the municipality wants, it can be printed and distributed and a web format can be put on internet. The

\footnotetext{
${ }^{\text {a }}$ The PPRi is a document elaborated by the local State, regulating the land use in the flood prone areas

${ }^{\mathrm{b}}$ Art. R125-10 code de l'environnement
} 
information about the availability of the document is given through a municipal notice posted during 2 months.

\subsubsection{The flood marks}

Installed in the flood prone zones, they indicate mainly 2 things: the level reach by previous floods or the highest known water level, and a history of the floods on the territory. The mayor (or the community of municipalities) is in charge of implementing the flood marks. The Prefect also participates.

In France the flood marks have the shape is defined at the national level: disc shape, an official pictogram, mainly hanging on buildings, it can also be installed on other supports.

Flood marks have to be hanging in public space and to be visible from the street. Their number considers the place layout, frequency and importance of floods and also the number of people visiting the place. They are referenced in the DICRIM. The sustainability of the information is ensured by the duty to maintain the flood marks and the possibility to establish public easement.

The State is currently establishing a data base on the existing flood marks.

\subsubsection{The IAL}

IAL is implemented for properties located in areas covered by a PPRn ${ }^{\mathrm{c}}$ or a PPRt ${ }^{\mathrm{d}}$ and in areas concerned by earth quakes. Properties traders and leaser have to implement the IAL.

The IAL is a one page standard form, completed with a text document on the history of the catastrophes and a map.

The IAL has to be systematically attached to the selling or renting contract. Both the seller/leaser and the buyer/tenant have to sign it.

\subsection{Are these tools, in theory, able to reach their objectives? Success factors of risk communication to obtain desired behaviours}

\subsubsection{Some influencing parameters of risk perception and behaviour adaptation}

To bring someone to adapt his behaviour to flood risk is a complex and reversible process. It request to intervene on the risk representation and on the individual involvement. Numerous parameters influence these 2 aspects.

The nature of the risk is an important one, for example a risk having a daily occurrence will be more easily accepted than a less frequent one. It is the same for a risk bringing a benefit [9]. Among these parameters age may play a role. But it is not always the same according to the contexts. Godfrin [10] shows that in the Alpes

\footnotetext{
c Natural Hazards Prevention Plan (PPRi is one of the different PPRn)

d Technological Risks Prevention Plan
}

Maritimes the over 66 years old were more in favour to individual empowerment in front of floods, while in the city of Pont de Clay the 30-59 years old (households with children) are feeling more concerned by major hazards [11]. The influence of the living environment [12], of the culture of the territory $\mid 13]$, or of the relation with the public authorities [14], is also important. The social norm may be considered as one of the most significant factors for the willingness to adopt appropriate safety behaviour, as "people are taking decision regarding their answer to a severe risk by consulting their family and in link with the community context" [9]. Finally, experience is frequently mentioned. It is an important factor but it may also have perverse effects as it do not systematically bring implementation of actions [10] or may give a false impression that there will not be more important event.

Toward Slovic \& al. [15], three main factors are important to take into account when the aim is to explain the flood risk perception: 1) is the risk frightening for people concern? 2) Is it known? 3) What is their personal exposition to this risk?

Moreover individuals have a better representation of risk when it is visible and when their lever of anxiety is very high on this topic [16]

To make effective risk communication, these influencing factors have to be considered but they have to be combined to factors intrinsic to communication.

\subsubsection{Success factors of risk communication actions and measures}

The analysis of numerous risk communication actions allows arising the main success factors of these actions and measures. We analysed some specific to the flood risk and some linked to other risks or other thematic requiring also behaviour adaptation from the population (like climate change). [5, 6] We selected 12 success factors to analyse the 4 tools. They are 12, spread in 6 categories.

- The $1^{\text {st }}$ category concerns the general presentation of the measure/tool and includes 4 factors:

- Is the tool based on a voluntary process or is it imposed? To convince concerned people to enter freely in the process is a prerequisite for a further sufficient involvement from them. The voluntary aspect of taking part in reinforces the receptiveness and individual involvement. But it is a limit to a mass participation of the population.

- Does the measure target a small or a large population? Individualized measures have an interesting potential to obtain a commitment of the people to adapt their behaviours. The individualized approaches require important human resources, which limits the number of actions that can be implemented. Priority is given to the "quality" more than to the "quantity". At the opposite, if more general actions do not allow giving specifically adapted messages to each personal situation, it allows to 
obtain a better coverage of the territory. Priority is given to "quantity" more than to "quality".

- Trainings in groups. To act efficiently to bring behaviour adaptations to face floods, training actions based on the creation of a group identity, but keeping the possibility to present the personal exposition to the risk are really interesting.

- Is the measure simple and easy to implement? This one is not a real success factor, but it is difficult to avoid it, the question of the available means is so much important for the practioners. According to the chosen objectives and to existing constraints (time, means...) the ease or the feasibility to implement the measure may be an important criterion to decide the action to take. But we can question the impact of a default choice.

- The strategy of the measure is a wide category as it comprises the whole measure and sometimes also different other measures or tools if the strategy works by steps with gradual targets and objectives. In a pragmatic way, we reduce it to only one factor: the creation of an environment favourable to the behavioural change. This can be made, for example, by ensuring societal, human and material conditions allowing the implementation of the recommendations.

- Is there an accompanying of the people? For example, to support the participants looking for more information and in their behaviour adaptation process.

- Methodological general principles:

- Choosing a communication focused on the person and on the solutions.

- Use resource people among the community, to make the information available in the targeted population and also to reinforce the credibility and the impact of the information.

- To make the communication continual: messages have to be explained and summarized at many times. To vary the sources, tools, methodologies for communicating reinforces the communication impact.

- Pedagogical and training conduction principles: using picture pedagogy may help to bring a better understanding. Maps may be used for this. Other pedagogical approaches may be interesting: experiential pedagogy and the reflexive approach.

- Messages: 2 success factors have been considered regarding the messages. The $1^{\text {st }}$ consist in bringing the popularized technical and scientific knowledge through educational and properly explained messages. The $2^{\text {nd }}$ one is that the messages give personal information regarding risk exposition, this in order to attract people attention and interest.

\subsubsection{Success factors barely taken in consideration by the 4 regulatory tools}

Most of the 4 evaluated tools (except IAL) provide messages, on the risk information and/or the proposed solutions, which are not focused on the persons but have a general scope. The use of resource persons among the communities and the consistency of the communication over time are unusual, except for the public meetings.

The functioning of some of the tools, using documents, may be considered as picture pedagogy. It is the case of the public meetings and the DICRIM. Effectively, to talk about floods is frequently done by using maps.

None of these tools proposes support or accompanying, they are based on a voluntary approach of the target (except IAL). Most of them are mass vector for awareness raising and do not provide personal information of the risk exposure to the targeted people.

These 4 tools do not consider setup a favourable environment for behaviour adaptation even if, due to their general by their broad scope and target, they participate.

They leave one to believe that risk information, without any accompanying or support is sufficient to change behaviours. These tools comply neither with the identified success factors nor with the factors of the socio-psychological studies.

\subsection{Why to propose an evaluation of the impact on the behaviours?}

The measures/tools setup by the policymaker to ensure the preventive information and achieve the objectives setup by the law do not take in consideration the success factors of risk communication. What is more, in the last flood events France had to face, we observe that amongst the people who lost their lives, an important part died because their lack of knowledge regarding the risk or because their risk taking behaviours.

But beside these statements, no real evaluation of the impact of these tools has been done. Some interesting studies exist that provide important information for the policymaker and the risk communicant or the territory manager but they do not assess the impact of the 4 tools on the behaviour of the targeted populations.

To fill this vacuum and to provide the risks and territory manager with a view of what can really been expected from these tools, the CEPRI proposes an evaluation of their impact on the risk perception and on the behaviours.

\section{How to measure the impacts of the French flood risk communication policy? Methodology aspects}

\subsection{Scale of perception and behaviour}

To assess the level of risk perception and the level of behaviour of the population we had to use and adapt some existing tools elaborating a scale of perception and behaviour. 


\subsubsection{A central point in behavioural change: risk representation}

If people do not perceive properly the reality of the risk they can neither intend to apply nor implement properly the prevention or protection behaviours. Authors [14] show that flood risk is frequently under-estimated or even not perceived by the concerned population. Important differences between scientific knowledge and layman's knowledge have also been noticed [17]. For the population, the estimation of risk is linked with the probability to personally experiment the social and physical negative impacts that a catastrophic event could bring up [18].

For floods [19], researches put forward that risk representation is interesting to predict individual decisions to adapt behaviours in front of natural hazards. To perceive the risk as 'important' increases the motivation to protection [20], and the higher the risk perception is, the most important is the adoption of protection behaviours.

If risk representation is central in the decision making process to take actions to protect yourself from flood, the full process of behavioural adaptation is complex, made of several steps and reversible. Its first step is the knowledge of the risk, which may lead to the awareness of the risk, and then to accept the risk. From this step of risk acceptation the effective behaviour adaptation may be set off. Different authors propose models to explain the process of change [21,22]. They explain steps of individual involvement in change and means to progress from one to another.

\subsubsection{Scale of perception and behaviours}

We based our scale of perception and behaviours on the transtheoretical model of Prochaska and Di-Clemente, crossed with the risk perception steps $[5,19]$, see table 1 below.

We associate the pre-contemplation, where the individual is satisfied with his situation and do not plan any change, to 3 steps of risk perception: the absence of knowledge, the incomplete knowledge, and the knowledge. The absence of knowledge correspond to the ignorance of the situation at risk, the incomplete knowledge correspond to the awareness of being at risk but without a real representation of the risk or with a wrong picture. This step also includes some dead-end attitudes like denial, unrealistic optimism and delegation [23]. Finally the knowledge step is characterized by the awareness of being at risk and the fact to have a risk representation corresponding to the reality.

The second step of our perception and adaptation scale is contemplation associated with consciousness and acceptation. In the contemplation phase, the individual feels the necessity of changing in a near future (more or less 6 months), but without knowing how to do or without having the means to do it. The consciousness is like the knowledge step but completed with the acute knowledge of the impacts and consequences of a flood for the individual, his family and belongings and the knowledge of the measures that can be taken. The acceptation step corresponds to the acceptance of the risk and of its potential impacts. This last step opens the door to the preparation.

The Third step is the preparation, where people are mentally ready to act and to elaborate action plans, the forth, Action, where people implement concrete actions and finally the maintenance step with the maintaining in the time of the newly adopted behaviour to ensure its sustainability. In these 3 last steps there is no risk perception progression anymore. Theoretically at this level, people are supposed to have all a full consciousness of the risk and to accept it. But our study will show that reality is a bit more complicated.

\begin{tabular}{|c|c|c|}
\hline $\begin{array}{l}\text { BEHAVIOUR } \\
\text { ADAPTATION }\end{array}$ & \multicolumn{2}{|c|}{ RISK PERCEPTION STEPS } \\
\hline \multirow{3}{*}{ Pre-contemplation } & \multicolumn{2}{|c|}{ Absence of knowledge } \\
\hline & $\begin{array}{l}\text { Incomplete } \\
\text { knowledge }\end{array}$ & \begin{tabular}{|cl} 
Dead-end attitudes : \\
- & denial \\
- & unrealistic \\
& optimism \\
- & delegation \\
\end{tabular} \\
\hline & \multicolumn{2}{|l|}{ Knowledge } \\
\hline Contemplation & \multicolumn{2}{|c|}{ Consciousness } \\
\hline Preparation & \multirow{3}{*}{\multicolumn{2}{|c|}{ Acceptation }} \\
\hline Action & & \\
\hline Maintenance & & \\
\hline
\end{tabular}

Table 1. Scale of perception and behaviours.

This scale has been used to classify the people of our survey sample. It helped us to have, for each individual, a global indicator of a quite complicated situation and to simplify the comparisons and cross checking.

\subsection{A qualitative study}

We choose to lead a qualitative study, using semidirective interviews to collect people perceptions, attitudes and behaviours. The outline of the interview was based on the perception and behaviours' scale.

We limited our sample to 32 persons. The duration of the interviews varied from 45 minutes to 2.5 hours, with an average around 1.5 hour.

Even if very interesting, allowing to go in deep in the understanding of the situation of each interviewee and to understand the risk representations, and drivers for change for those who already undertook some actions, this kind of methodology has also some limits, mainly in terms of representativeness.

After the assessment, we also organised a meeting gathering some interviewees, elected representatives and engineers of Orleans city council. This allowed to share the results and to debate. Beside the interesting confrontation between population and administration, it was also an opportunity to discuss the way to improve the tools and more generally the preventive information. 


\subsection{The city of Orléans as case study: potentially significant flood risk and a population with a lost flood risk culture}

Orleans is the most Northern town of the Loire River. 22000 persons live in the flood prone area (and 60000 for the entire Val d'Orléans), protected by dikes. It is the second most exposed area of Loire. Orleans was severely flooded in the $19^{\text {th }}$ century, hit 3 times between 1846 and 1866 by $1 / 100$ or more return period floods, with dikes breaches and an average water level of 1.5 meter. In case of such major flood, the water may stagnate one week. But since, except a less important event in 1907 (without dike breach) the territory did not experience flood anymore.

Local authorities are involved in an evacuation plan for the 60000 persons at risk. The local dynamic of major floods is characterized by a warning period of 4-5 days and 48 hours to implement the evacuation of the population, before the water floods the territory. The water may reach until 4 meters of height. An important part of the success of the crisis management plan relies on the fact that the population will follow the evacuation order if requested to do so.

The city of Orléans is in charge of implementing 3 of the 4 measures/tools of preventive information (DICRIM, flood marks and public meetings). It is important to note that Orléans respects all the legal requirements of the information of the populations regarding flood risk. There is no bias regarding this aspect.

There are 50 flood marks spread all over the flood prone area, the first DICRIM was issued in 2004 and the new one in May 2013 years ago, they have been made available at the central city hall and in the annexes, with information in the city hall and in the city magazine, publics meetings are regularly organised, the last ones for the new Flood Risk Prevention Plan one year ago. Finally the IAL is implemented in Orléans since 2006.

Some others communication actions are also implemented by the city or other stakeholders, participating to raise the awareness of the population. This links with the fact that the population of Orléans has potentially many various sources of information (including media and NTIC). This constitutes a methodological stake for us: to be able to identify the impact of each of the 4 tools amongst all the flood risk information sources. What is more awareness may also be connected with some other flood risk management measures, like dikes maintenance, works on the river bed, or with urbanisation planning and development.

\subsection{Our population sample}

\subsubsection{Selection}

The areas selected for our study have been chosen with the engineers of the city council in order to ensure the best representativeness of our sample. 6 districts have been selected due to their exposure to flood risk and their diversity in terms of housing and population type.

INSEE, French National Institute of Statistics and Economic Studies ${ }^{\mathrm{e}}$ provide statistical information on the populations at different territory levels. The more accurate available is the IRIS $^{\mathrm{f}}$ level. Our 6 districts correspond to 9 IRIS. We combined them together to analyse the representativeness of our sample areas. The following chart gives the correspondence.

\begin{tabular}{|c|c|}
\hline Number and name of IRIS & Targeted areas \\
\hline 1201 Saint-Laurent-Sanitas & North Orleans (the quays) \\
\hline 1301 Fiacre-Chenault & $\begin{array}{l}\text { Heart of the Saint Marceau } \\
\text { district }\end{array}$ \\
\hline 1401 Plantes-Dauphine & \multirow{2}{*}{$\begin{array}{l}\text { South part of the George V } \\
\text { bridge }\end{array}$} \\
\hline 1601 Mouillère-Dauphine & \\
\hline 1501 Les Roses & $\begin{array}{l}\text { South of the Saint Marceau } \\
\text { district }\end{array}$ \\
\hline $1701 \mathrm{Sud}$ & Parc des expositions \\
\hline 1502 Cigogne & \multirow{3}{*}{ Saint-Mesmin Avenue } \\
\hline 1702 Sud-ouest Chabassières & \\
\hline $\begin{array}{l}1703 \text { Ouest-Corne de Cerf- } \\
\text { Guignegault }\end{array}$ & \\
\hline
\end{tabular}

Table 2. Correspondence of IRIS and targeted districts

We selected the following parameters to compare our sample to the population of the corresponding IRIS and of the city of Orleans:

- the structure of the population number of women, men, socio-professional category, ...)

- the structure of households (single, in couple, with children...)

- the professional activities

- the housing (tenant or owner, apartment, house, date of entry, ...)

- diplomas and educational level

They are corresponding to variables potentially influencing the risk perception and behaviour adaptation mentioned in the literature.

\subsubsection{Overview of the sample characteristics}

The IRIS corresponding to our selected districts have characteristics close to the characteristics of the general population of Orléans. But the persons who participated to the survey are not fully representative of the IRIS they live in.

In a general way, if they are more women than men, like in the general population, it is not in the same proportions ( 21 women for 11 men in our sample). Like

\footnotetext{
e The French National Institute of Statistics and Economic Studies is a Directorate-General of the Ministry for the Economy and Finance. INSEE's mission is to collect, analyse and disseminate information on the French economy and society across the entire French territory. f IRIS stands for "gathered houses clusters for statistical information", it is the most accurate unit available for statistical information at the infracommunal level
} 
for the rest of the population, our sample is in majority settled in his current accommodation since 10 years or more.

But our sample presents population older than the general one, more often owner of his house or apartment and living more frequently in individual houses.

We faced some difficulty to recruit volunteers for the interviews. This difficulty impacted the repartition of the number of persons interviewed in the town districts and in the corresponding IRIS (given in the table 3). For the north part of Orléans we could not find any participant and the repartition of the number of persons is not proportional to the population size of each IRIS.

\begin{tabular}{|l|l|c|}
\hline IRIS num. & \multicolumn{1}{|c|}{$\begin{array}{c}\text { Corresponding targeted } \\
\text { area }\end{array}$} & $\begin{array}{c}\text { Num. of } \\
\text { persons } \\
\text { interviewed }\end{array}$ \\
\hline IRIS n ${ }^{\circ} 1301$ & $\begin{array}{l}\text { Heart of the Saint Marceau } \\
\text { district }\end{array}$ & 6 \\
\hline IRIS n ${ }^{\circ} 1401$ & $\begin{array}{l}\text { South part of the George V } \\
\text { bridge }\end{array}$ & 3 \\
\hline IRIS n ${ }^{\circ} 1501$ & $\begin{array}{l}\text { South of the Saint Marceau } \\
\text { district }\end{array}$ & 4 \\
\hline IRIS n॰1601 & $\begin{array}{l}\text { South part of the George V } \\
\text { bridge }\end{array}$ & 5 \\
\hline IRIS n॰1701 & Parc des expositions & 1 \\
\hline IRIS n $^{\circ} 1702$ & Saint-Mesmin Avenue & 2 \\
\hline IRIS n $^{\circ} 1703$ & Saint-Mesmin Avenue & 11 \\
\hline
\end{tabular}

Table 3. Repartition of our sample in town districts and in IRIS

Our sample is composed of 32 persons, 21 women and 11 men. The average age is 36 years, the minimum 22 and the maximum 86. The median value is 52 years.

Among the interviewed people we have 21 persons with professional activity and 11 inactive ( 9 retired and 2 students). 24 are in the high socio-professional category and 8 in the low one.

20 persons are owners of their accommodation, 12 are tenants; 22 are living in houses and the rest in apartment. 24 have settled more than 10 years ago and 8 since less than 3 years. 10 persons think that they may possibly move in the coming months (there is no link with flood risk).

In our sample 16 persons have children still living with them.

\section{Which impact of the regulatory flood information tools on the population?}

\subsection{Risk perception of the flood zone inhabitants}

\subsubsection{A population in a situation of "incomplete knowledge"...}

As shown by the graphic below, the major part of our sample (20 persons) is in the step corresponding to an incomplete knowledge. They know to live in flood prone area but their representation of the risk is either incomplete or corresponding to flash floods like those that occurred the last years in the South of France. Beside this, it is important to notice that 30 persons know they are living in flood prone area.

2 persons are in the knowledge stage, 1 in consciousness and 6 in acceptation. We have also 1 person not knowing being at risk and 2 engaged in deadend attitudes: 1 in denial, the other in delegation.

A majority of the interviewees do not know the impact of a flood for Orleans and for their accommodation.

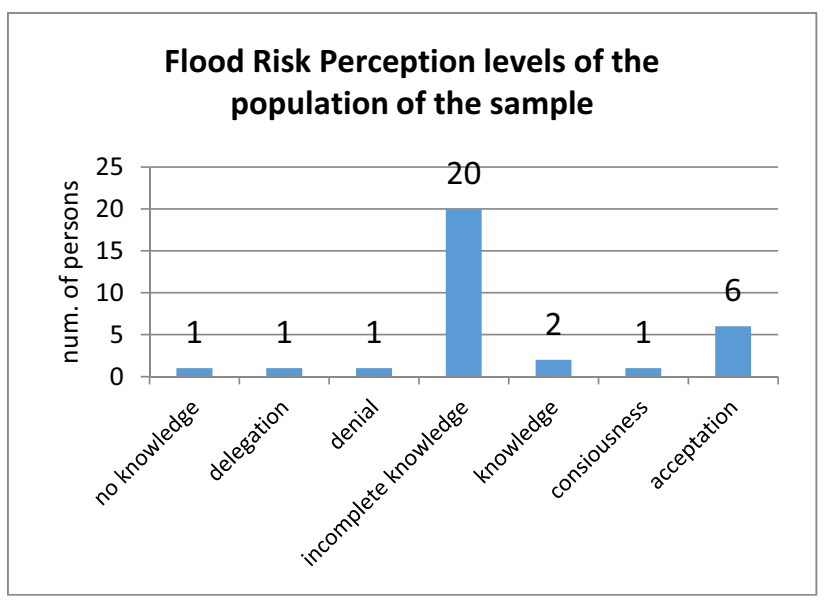

Figure 1. Sample repartition in the risk perception steps.

\subsection{2. ...And a declarative "acceptation" of the risk differing from our understanding}

A declarative risk acceptation was also measured. It differs from the step of "acceptation" of our perception and behaviour scale.

We used the questions "How do you feel with the fact you are living in a flood prone area?" and "Is that part of your daily preoccupations?" It was also completed with other elements coming from the rest of the interview.

From the answers to these questions we obtain 27 persons saying they accept the risk, meaning that they believe a flood can occur in Orléans and they accept the fact to live in the flood prone zones. It is important to note that among these 27 persons 19 have an erroneous risk representation. They base their acceptation on far less lower impacts than the reality would be.

\subsubsection{What do the people knows about floods in Orléans?}

We defined the 4 main characteristics of the floods in Orléans: i) warning time, ii) water levels, iii) flood duration and iv) mass evacuation necessity. Those 4 parameters are characterising the floods in Orléans. The height of water and the stagnation duration indicate the magnitude of the floods and are prerequisites to understand the consequences (physical impacts, necessity to evacuate, duration of the evacuation...). The warning time may allay fears, helping people to understand that they will have (little) time to prepare to evacuate. And the mass evacuation is the protective measure of the 
authorities. In the Orléans' area not to know that people will have to evacuate, and not be prepared to, may expose the people to severe risks.

We questioned our interviewees on their knowledge on these parameters and gave a mark out of 4 . The graphic below presents the results.

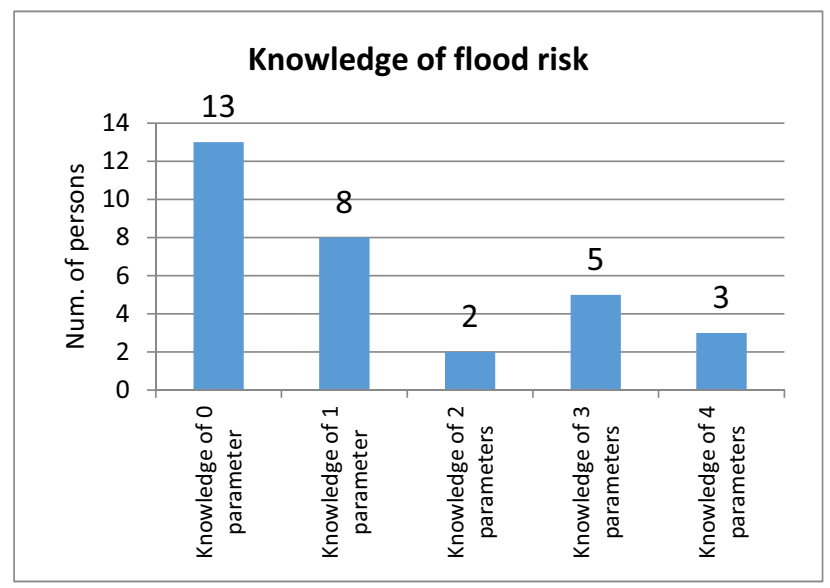

Figure 2. Knowledge of flood risk in Orléans.

It is really important to notice that almost half of our sample does not know any parameter characterising the flood. They know living in a flood prone area but they are in a complete ignorance of what does it means. Only 3 persons really know what would be a flood in Orléans.

The best known parameter is the mass evacuation of the Val d'Orléans (14 persons), the second the water levels (known approximately by 13 persons), the third the warning time (11 persons) and finally the duration of the water stagnation (3 persons).

\subsubsection{Are people stressed by the floods?}

We determine, using the verbatim of the interviews, if the people of our sample were feeling comfortable or not with the idea of living in flood prone areas. We choose to not asking them directly to avoid the bias of cognitive dissonance. 27 persons seem being psychologically comfortable and 5 in psychological discomfort. Regarding the potential magnitude of the risk we consider this rate of $15.6 \%$ of our sample being quite low, but probably a bit exaggerated regarding the general population.

\section{2 information sources}

The population of our sample has a very heterogeneous level of knowledge regarding flood risk (from "expert" level to absence of knowledge). We noticed an evolution between the installation time and the current time. At the moment of the survey 30 persons over 32 know they live in flood prone area, but at the time of the choice of their living place they were only 13 . This questions the ways the people learn their exposition and gain their knowledge on the floods.

\subsubsection{For the situation in flood prone zone}

The main information source for the people to learn their exposition to flood risk is a direct deduction from their proximity with the river. It is cited by 9 persons of our sample. For 8 persons this situation is known by word from mouth and for 6 persons by the professional life. Only one of the 4 regulatory tools participates to this information: the flood marks, cited by 5 persons. Some other regulatory documents from the local authorities are also names 5 times. And, finally the building permit, for 4 persons. The answers with fewer occurrences have not been considered.

It is interesting to note that the 3 main sources of information about the fact to live in flood risk zone do not have any link with the authorities or with official or regulatory documents. People manage by themselves to get this information.

\subsubsection{On the flood risk}

Once informed about their situation at risk, people may receive some complementary information. We asked them how they are informed about flood risk and what their sources of information are.

The answers have been classified according to their occurrence. They are presented in the table 4 (those with occurrences fewer than 5 are not mentioned).

\begin{tabular}{|c|l|}
\hline $\begin{array}{c}\text { Number of } \\
\text { persons who cite }\end{array}$ & Known flood risk information source \\
\hline 32 persons & Flood marks \\
\hline 11 persons & Personal networks and word to mouth \\
\hline \multirow{3}{*}{9 persons } & $\begin{array}{l}\text { Regulatory documents from local } \\
\text { authorities, excepting the 4 regulatory tools }\end{array}$ \\
\cline { 2 - 2 } & Historical and cultural documents \\
\hline 8 persons & National medias (newspapers, TV...) \\
\hline \multirow{3}{*}{7 persons } & $\begin{array}{l}\text { The communications actions of the city } \\
\text { (excepting the 4 regulatory tools) }\end{array}$ \\
\cline { 2 - 2 } & professional life \\
\cline { 2 - 2 } & Cultural events \\
\cline { 2 - 2 } & Information board on the River water level \\
\hline \multirow{2}{*}{6 persons } & Public meetings \\
\cline { 2 - 2 } & Local medias (newspapers, TV...) \\
\hline 5 persons & Internet \\
\hline \multicolumn{2}{|c|}{ Table 4. Passive flood risk information sources classified } \\
according to their occurrence
\end{tabular}

Only one of the 4 regulatory tools is mentioned by the participants as information source. This means that everyone in our sample know the flood marks.

Once again the personal network and the word to mouth, informal ways of communicating, have a great importance in the risk information acquiring process; passive process until now.

4.2.3. Those who are specifically looking for information are not using the regulatory tools 
In our sampling 12 persons declare they are looking for information by themselves, in a proactive and dynamic way. They explain doing it because they are interested by the topic (5persons), for a personal or professional project (3 persons), in order to protect their accommodation (2 persons) and to keep a close watch on the Loire River (1 person), one person did not give reason.

The information sources of these persons, actively involved in information research, are differing from the previous mentioned, but still do not include the regulatory preventive information tools. Please see the table 5 .

\begin{tabular}{|l|l|}
\hline $\begin{array}{c}\text { Num. of } \\
\text { persons } \\
\text { who cite }\end{array}$ & \multicolumn{1}{|c|}{ Used flood risk information source } \\
\hline 6 persons & National Agencies (water management...) \\
\hline 5 persons & $\begin{array}{l}\text { Vigicrues (online flood risk prevision map } \\
\text { based on real time forecasts) }\end{array}$ \\
\hline 4 persons & Urban planning documents \\
\hline 3 persons & Flood Risk Prevention Plan ${ }^{\mathrm{g}}$ (PPRi) \\
\hline 2 persons & Local authorities documents \\
\hline \multirow{3}{*}{1 persons } & Family safety plan \\
\cline { 2 - 2 } & Internet \\
\cline { 2 - 2 } & Orleans City web site \\
\cline { 2 - 2 } & Postal card and old photographs \\
\hline
\end{tabular}

Table 5. Information sources of people actively seeking.

\subsubsection{How many persons know the regulatory tools?}

Besides the flood marks, known by our entire sample, the other regulatory tools are not well known. 6 persons know the public meetings and have attended some, 3 persons know the IAL (over the 8 persons concerned of our sample, those who install themselves since 2006) and 2 the DICRIM.

Except for the flood marks it seems that the dissemination of the preventive information regulatory tools is a real problem as they do not reach their targets.

\subsubsection{What impact of the regulatory preventive information tools on the flood risk perception?}

Every interviewee knows the flood marks, but the quality of the message given by this tool is questionable. Indeed, we have 13 persons not having any idea of the floods parameters and only 13 who know approximately the expected level of water. The interviewees explained us that they know the old flood marks installed near the river but not the new ones, respecting the regular shape, spread all over the flood prone area. What is more it is very difficult for them to link the level of water indicated by the mark to the height of water in their house or building. The information the flood marks are supposed to provide finally does not reach their target. Flood mark is more an historical thing people like to show than a real proof of danger for themselves and their living area.

\footnotetext{
${ }^{g}$ Flood Risk Prevention Plan, elaborated by the State, sets overarching rules for spatial planning and construction in flood prone zones
}

Among the 6 persons who know the public meetings (and the flood marks) 4 do not know the other tools. These 4 have an average rating to the knowledge of flood parameters of 2.75 , just a bit below those who also know the DICRIM (average rating of 3 ).

3 persons know the IAL (and also the flood marks) and have a flood knowledge rating of 0.66 (far under the sample average rating: 1.3 ). The IAL does not seem to have any impact on the knowledge on flood.

But it is difficult to separate the effects of one or the other tools, these results have to be considered just as indications. In a global way, as it is shown by the figure 3 , we can consider that there is a link between both the number of regulatory tools known, the number of total information sources and the knowledge of the flood parameters. If the impacts of the different regulatory tools are difficult to separate one from another, it is the same with the other information sources.

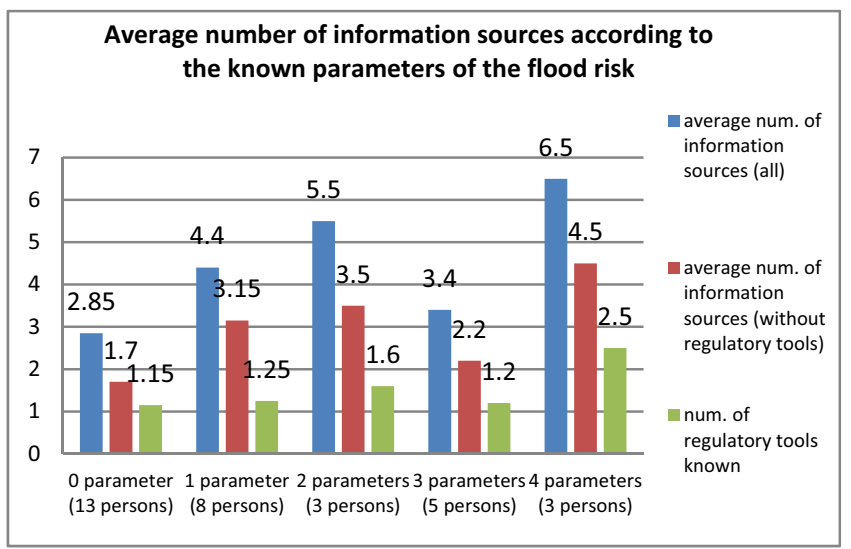

Figure 3. Average number of information sources according to the known parameters of the flood risk.

\subsection{Actions and actions' intentions}

Our survey, following the objectives of the preventive information, questioned the intentions of action and the actions implemented by the people of our sample.

\subsubsection{Actions already implemented}

8 persons have already implemented some actions to prevent flood risk. They are presented in the table 6 .

\begin{tabular}{|c|l|}
\hline $\begin{array}{c}\text { Num. of } \\
\text { persons }\end{array}$ & \multicolumn{1}{c|}{ Action implemented } \\
\hline 6 persons & $\begin{array}{l}\text { Important documents preservation (copy, scanned } \\
\text { and store on CD or usb key) }\end{array}$ \\
\hline \multirow{2}{*}{4 persons } & $\begin{array}{l}\text { Structural measures in the house (like electrical } \\
\text { network...) }\end{array}$ \\
\hline \multirow{2}{*}{3 persons } & $\begin{array}{l}\text { Anticipation of a place where to live during } \\
\text { evacuation period }\end{array}$ \\
\hline 2 persons & Listing of the goods to move and protect \\
\hline \multirow{2}{*}{1 persons } & Cofferdam ready \\
\cline { 2 - 2 } & Material for the return after evacuation \\
\cline { 2 - 2 } & Listing of the emergency phone numbers \\
\cline { 2 - 2 } & Preparation of the family safety plan \\
\hline
\end{tabular}

Table 6. Actions undertaken and corresponding number of people. 
The people who already implemented actions to prevent flood know, in average, 1.87 regulatory preventive information tools, have 3.5 other sources of information and a rating of 2.65 for the flood parameters knowledge. Our global sample marks are respectively: $1.34 ; 2.65$ and 1.28 . The people who implement action by themselves have a better knowledge of the floods, know more regulatory tools and have more information sources than the average population of the sample. It worth noting that they also are more stressed by the floods than the average population: among the persons who implemented actions $37.5 \%$ are in psychological discomfort while they are only $15.6 \%$ in our sample global population.

\subsubsection{Actions' intention}

We ask the interviewees to give us the actions they would implement to face the floods, in case of an event occurring. It is interesting to note that only 3 of them imagine action in anticipation. The rest of our sample (except those who already implemented some actions) does not imagine that they can anticipate.

The main answers given regarding the reaction to face a flood are:

\begin{tabular}{|l|l|}
\hline $\begin{array}{c}\text { Number of } \\
\text { persons }\end{array}$ & \multicolumn{1}{c|}{ Action proposed } \\
\hline 14 persons & To evacuate \\
\hline 8 persons & To move to the upper floors \\
\hline 7 persons & To turn off gas and electricity \\
\hline 6 persons & To move belonging in the next floor \\
\hline 5 persons & To find a place where to go during flood \\
\hline
\end{tabular}

Table 7. Actions foreseen and corresponding number of people.

14 persons say they will evacuate in case of flood event, which is the expected behaviour. But 3 of them would evacuate in the upper floors or to a neighbour house... It is important to precise that authorities consider not possible to stay in the upper floors of a house during one week in the conditions of a flood in the Val d'Orléans (no network available, no movement possible, only few evacuations possible...). According to the risk perception of the people those who considers the evacuation imagine it for few days, and not for the weeks (or even months) it will really last.

\subsection{Behaviours' stages}

The main part of our population sample is in the step of pre-contemplation, not perceiving any problem with their current situation. In the contemplation and preparation steps, which are transitional steps, we have only one person in each. The steps corresponding to active behaviour in front of floods contain 3 persons each.

Can we make a link between the steps and the knowledge of the regulatory tools?

As shown by the figure 4, there is an increasing of the average number of known regulatory tools with the progression in the perception and behavioural scale. But we cannot say that people adapted their behaviour because they know these tools. We know that these persons are also those who are more looking for information on floods and they may have adapted their behaviour before finding the regulatory tools.

But we can say that there is effectively a concordance in the fact of being in the more advanced steps of the scale and to know the tools.

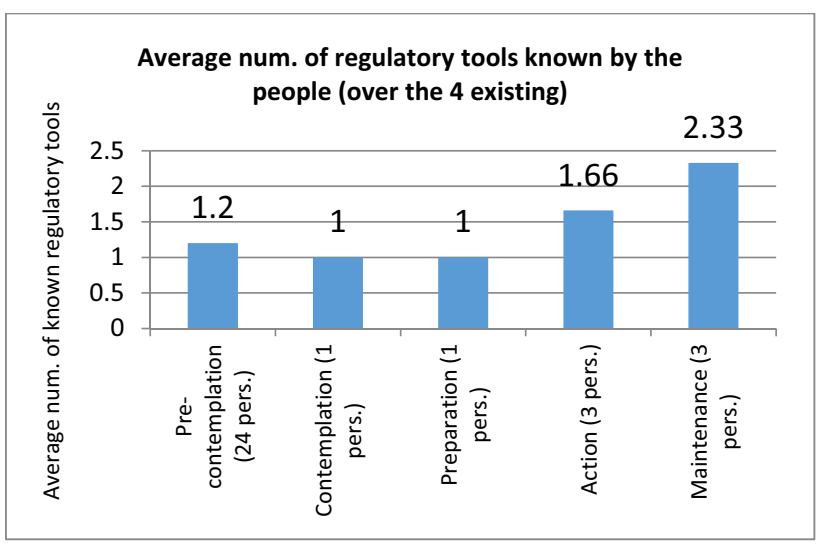

Figure 4. Average number of regulatory tools known by the people according to their step in the behaviour scale.

\subsection{The psychological discomfort as key factor}

Another factor appears to be important to explain the behaviours of our population sampling: the psychological discomfort. It is linked to the information seeking, to the action implementation, to the number of information sources, to the number of known regulatory tools, and to the positioning in the risk perception and behaviour scale. Figure 5 shows this last link.

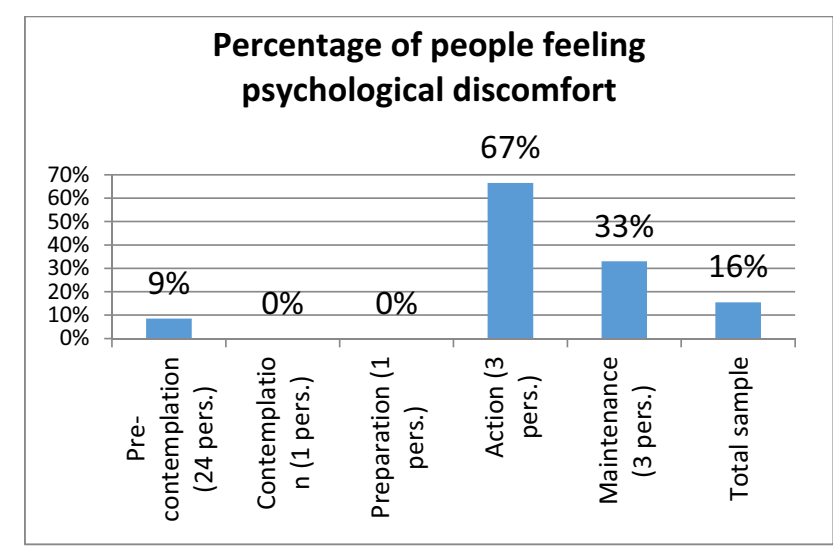

Figure 5. Percentage of people feeling psychological discomfort according to their position in the behaviour adaptation scale.

An interesting point is that this discomfort takes place in context where the risk, the threat is not really visible and where flood has a very low occurrence these last 150 years.

Here also we face this "chicken and egg question". Do the people of our sample know the preventive information regulatory tools because they were looking for information about floods, pushed by their stress, or did they get stressed because they learn information on flood risk through the regulatory tools? 
As it is explained by the literature a high level of worry is linked to an increased risk perception and to implementation of protection behaviours. 2 important factors for increased risk perception are the novelty of the risk and the felt level of worry and fear associated to the risk [24].

\section{Discussion}

\subsection{Regarding the study}

\subsubsection{A study that would request duplication and comparison}

The risk perception, central element for behavioural adaptation, may be influenced notably by the territory and the flood events and their history, the type of floods... We completed this study only in one territory but we are on progress on a second territory, the city of Arles, in the south of France, where people faced flash floods 10 years ago and where the flood memory is still strong. The comparison of the 2 areas will bring new interesting elements.

\subsubsection{A sample probably not representative of the global population}

Our population sample size of 32 persons corresponds to a qualitative study. It is not suitable for quantitative or statistical interpretations and we cannot provide reliable estimates for the whole flood risk area's population.

We interviewed the people willing to participate to our survey. This suppose that they were already interested by the subject of flood risk and that they, probably, are more informed than the general population living in the flood prone area of Orléans.

Thus we have to consider our results as a bit too "optimistic" regarding the knowledge of the preventive information regulatory tools the position of the population in the perception and behaviour scale, and the ability of the population to anticipate and to be ready in front of a flood.

For the local authorities the step is probably even much higher than our evaluation's results say.

\subsubsection{Limits of our perception and behaviour scale model}

In our sample we noticed that some people without having a correct perception of the flood in Orléans city, already implemented actions. These actions are not always completely adapted, but these people could be considered as being in the action or maintenance steps of our model with an erroneous or incomplete knowledge.

We had to nuance our theoretical model of perception and behavioural scale. We took in consideration the fact that the study shows that it is possible to reach the 3 last steps of the scale without a proper risk perception and added to these steps description the possibility to mention the incomplete or inadequate flood risk perception.
But whatever is the relevance of the risk perception, we noticed a common denominator: the perception of the consequences and impacts of the flood and the fear to have to face it, even if based on a wrong flood picture or scenario. This may be a very important point for the policymaker and for the territory and risk manager.

\subsection{Regarding the regulatory tools and preventive information in general}

\subsubsection{A theory of action based on 2 debatable principles}

People will look for information by themselves. One important principle of the regulatory tools, except for the IAL, is that the mayor makes the information available and the people will come to the city hall to get it (DICRIM).

Regarding the number of people knowing about the DICRIM the public meetings or even the IAL (which is mandatorily signed during the rent or sale contract signature), obviously, it does not work. The people do not have the information of the existence of the tools. Or when they know it (flood marks), they cannot interpret and use the provided information for their personal situation. What is more, in Orléans, the people knows the old floods marks, installed in the 19 s century which gives to the information an historic character, but also the impression that floods are something belonging to the past and makes a new event, in our current times, less credible.

The preventive information's theory of action is also based on the fact that, once informed about floods, people will "automatically" adopt adapted behaviours.

But studies show that this link is far more complicated and that in most of the cases just receiving information does not makes people adapting their behaviours [25]. It is also what explains our risk perception and behaviour scale, presenting all the remaining successive steps once knowledge of flood is acquired.

These 2 statements, base of the preventive information functioning, are by their nature limiting the potential impact of the implemented actions, hampering the achieving of the policymakers goals.

\subsubsection{The use of success factors to improve the preventive flood risk information?}

Beside the fact that the regulatory tools do not reach their targets, they do not take in consideration the basic success factors necessary to improve the risk (and its consequences) perception and to push people entering in the process of behaviour adaptation.

Due to the very low penetration rate of the tools (except flood marks) among the people targeted it is finally difficult to apprehend really their impact on a large population.

Whatever, to consider the success factors in the elaboration and in the implementation of flood risk communication actions would help to improve the 
existing tools and maybe lead to propose complementary ones.

\section{Conclusion}

We notice this link, already highlighted in the literature, between psychological discomfort and upper steps of our scale. The interpretation can be done in 2 ways having different consequences for preventive information and the territory manager.

The 1st possibility is that flood risk information stress people. In this case we have to ask ourselves what do we want to achieve? A population with a stress of everyday life and a population able to act appropriately and who will probably avoid a part of the post event stress. Or a serene population in the everyday life but that may only partly react in an appropriate way in crisis time and face stronger psychological difficulties in post crisis period.

The second possibility is that the people are looking for information because they are stressed. This could be a dead-end situation as in these conditions we can only inform stressed people which represent a small part of our population.

These 2 possibilities are valid if we consider that the preventive information tools and measures, not only the 4 regulatory ones, will not evolve. In this situation, regarding the results we have to consider that the "culture of risk" (understood as a population with adequate risk perception, serene and prepared to act appropriately) so frequently highlighted is a myth. To change this we need to innovate in our way to communicate about flood risk.

\section{References}

1. MEDDE (2012). Mieux savoir pour mieux agir Principaux enseignements de la première évaluation des risques d'inondation sur le territoire français EPRI 2011.

2. Ifop. (2011). The national barometer on water resources and wetlands preservation.

3. Vinet, Boissier, Defossez (2011). La mortalité comme expression de la vulnérabilité humaine face aux catastrophes naturelles: deux inondations récentes en France (Xynthia, Var, 2010). Vertigo - la revue électronique en sciences de l'environnement, volume 11, numéro 2.

4. Potard E. (2015). Les français face aux risques environnementaux, Etudes \& documents $\mathbf{n}^{\circ} \mathbf{1 2 8}$, CGEDD.

5. CEPRI (2013). Sensibiliser les populations exposées au risque d'inondation - Comprendre les mécanismes du changement de la perception et du comportement.

6. JADOT J. (2015). Communication actions for people awareness on flood risk: Evaluation of impact on behavioural changes. Congrès SHF/AFEPTB: "Gestion des risques d'inondation», Paris, mai 2015.

7. Loi $\mathrm{n}^{\circ}$ 2004-811 du 13 août 2004 de modernisation de la sécurité civile.

8. Maquette nationale pour l'application du code de l'environnement articles L 125 - 2 et R $125-5$ à R 125 - 27. MEDDE, mise à jour du 16 janvier 2013.
9. O’Neill, P. (2004). Developing a risk communication model to encourage community safety from natural hazards.

10. Godfrin, V. et Al. (2002). Rapport d'étude du programme Évaluation et prévention des risques.

11. http://www.irma-grenoble.com/01actualite/01articles afficher.php?id actualite $=328$

12. DIREN Rhône Alpes, (Février 2007). Le risque inondation dans la vallée du Rhône : postures riveraines du Haut-Rhône au delta.

13. MEDD (D4E). (2003). Etudes psychosociologiques concernant l'information et l'alerte pendant l'épisode extrême du 8 et 9 septembre 2002

14. Weiss, K., Colbeau-Justin, L. \& Marchand, D. (2006). Entre connaissance, mémoire et oublis : représentation de l'environnement et réaction face à une catastrophe naturelle. In Weiss \& D. Marchand (Eds.), Psychologie sociale de l'environnement. (p.63-73). Presse Universitaire de Rennes.

15. Slovic P, Fischhoff B, and Lichtenstein S. (1980) "Facts and Fears: Understanding Perceived Risk" Societal Risk Assessment: How Safe is Safe Enough. Edited by Richard Schwing and Walter Albers, Plenum Press, pp. 181-214.

16. Miceli, R., Sotgiu, I., Settanni, M. (2008). Disaster preparedness and perception of flood risk: A study in an alpine valley in Italy. Journal of environmental psychology, vol 28, issue 2, pp. 164-173.

17. Slovic, P., Finucane, M.L., Peters, E., MacGregor, D.G (2004). Risk as analysis and risk as feelings: some thoughts about affect, reason, risk and rationality. Risk analysis, vol. 24, Issue 2, pp. 311322.

18. Mileti, D.S., Peek, L. (2000). The social psychology of public response to warnings of a nuclear power plant accident. Journal of Hazardous Materials, 75, pp. 181-194.

19. Grothmann, T.et Reusswig, F. (2006). People at risk of flooding: Why some residents take precautionary action while others to not? Natural Hazards, 38, pp. 101-120.

20. Floyd, D.L, Prentice-Dunn, S., Rogers, R.W. (2000). A meta-analysis of research on protection motivation theory, Journal of Applied Social Psychology. 30, pp. 407-429.

21. Prochaska, J.O., \& DiClemente, C.C., (1982). Transtheoretical therapy: Toward a more integrative model of change. Psychotherapy: Theory, Research \& Practice, 19(3), 276-288.

22. Heckhausen, H. \& Gollwitzer, P. M. (1987). Thought contents and cognitive functioning in motivational versus volitional states of mind. Motivation and Emotion 11, 101-120.

23. Kouabenan, D.R., (2007). Incertitude, croyances et management de la sécurité, Le travail humain, P.U.F, 2007/3 vol.70, pp. 271-287.

24. Slovic, P. (1987). Perception of risk. Science, 280285.

25. Bradford R.A.et al. (2012). Risk perception - issues for flood management in Europe. Nat. Hazards Earth Syst. 